\title{
Microstructure Characterization of Aluminium Syntactic Functionally Graded Composites Containing Hollow Ceramic Microspheres Manufactured by Radial Centrifugal Casting
}

\author{
S.C. Ferreira ${ }^{1, a}$, A. Velhinho ${ }^{1, b}$, L.A. Rocha ${ }^{2, c}$ and F.M. Braz Fernandes ${ }^{1, d}$ \\ ${ }^{1}$ CENIMAT, Materials Research Center, Faculty of Science and Technology, New University of \\ Lisbon, Quinta da Torre, 2829-516 Caparica, Portugal
}

${ }^{2}$ CIICS, Research Centre on Interfaces and Surfaces Performance, Mechanical Engineering Department, University of Minho, 4800-058 Guimarães, Portugal

asccf@fct.unl.pt, bajv@fct.unl.pt, 'Irocha@dem.uminho.pt, dfbf@mail.fct.unl.pt

\begin{abstract}
Keywords: Aluminium syntactic functionally graded composites, Hollow microspheres-reinforced composites, Centrifugal casting, Quantitative image analysis.
\end{abstract}

\begin{abstract}
Syntactic functionally graded metal matrix composites (SFGMMC) are a class of metallic foams in which closed porosity results from the presence of hollow ceramic microspheres (microballoons), whose spatial distribution varies continuously between the inner and the outer section of the part, thus resulting in a continuous variation in properties. In this work, aluminiumbased SFGMMC rings were fabricated by radial centrifugal casting. The graded composition along the radial direction is controlled mainly by the difference in the centrifugal forces which act on the molten metal matrix and the ceramic particles, due to their dissimilar densities. In this case where the density of the $\mathrm{SiO}_{2}-\mathrm{Al}_{2} \mathrm{O}_{3}$ microballoons is lower than that of molten aluminium, the particles show a tendency to remain closer to the inner periphery of the ring. Thus the microballoon volume fraction increases along the radial direction of the ring from the outer to the inner periphery; in other words, the particle-rich zone is limited to an inner layer of the ring. Precursor conventional MMCs were prepared by stir-casting from the constituent materials, by homogeneously dispersing commercial $\mathrm{SiO}_{2}-\mathrm{Al}_{2} \mathrm{O}_{3}$ microballoons (particle size: $50 \mu \mathrm{m}$; particle volume fraction: 5 and $10 \%$ ) within a molten commercial Al-7Si-0.3Mg (A356) alloy. The resulting MMCs were then re-melt and centrifugally cast in order to produce the functionally graded composites. Particle gradients in the centrifugally cast composites were investigated by quantitative image analysis of optical micrographs (for the estimation of the particle volume fraction, mean particle diameter and porosity volume fraction).
\end{abstract}

\section{Introduction}

Recently, syntactic composites have been produced by the incorporation of hollow spherical particles (carbon, glass, alumina and other materials) in polymer and metallic matrices [1-2]. Their main advantage over conventional particulate-reinforced composites consists in potential weight gains and improved energy absorption capacities, as result of the void space within the reinforcements [1-4]. As a result, these materials have received some interest for marine and aerospace commercial applications [5].

Syntactic metallic foams containing hollow ceramic spheres (microballoons) can be fabricated using conventional metal matrix composite (MMCs) casting techniques [2]. Aluminium / microballoon foams have higher densities than conventional closed cell metallic foams produced, for example, by injecting gases into the melt. The advantage of the syntactic foams is to contain stiff and strong ceramic shells which increase the foam stiffness and strength. Thus, these ceramic shells act as reinforcing agents within the metallic matrix, in a similar fashion to what happens in conventional MMCs. Furthermore, their closed-cell geometry is attractive for energy absorption and insulating properties $[2,6]$.

The presence of voids in any material has a significant influence on its physical and mechanical properties. In syntactic metallic foams, two types of voids may be present: the cavities enclosed by 
the hollow particle shells and matrix porosities. The cavities are enclosed within the microballoons, and constitute the desired type of porosity. The cavities characteristics are controlled through the selection of microballoons with appropriate parameters (size, wall thickness and volume fraction) [5]. As to matrix porosity, it is generally undesirable, due to its degrading effect on the composite properties [5]. This porosity is generated during the fabrication process, due to gases entrapped within the matrix or adsorbed at the surface of the particles, to hydrogen evolution during cooling from the melt and to metal shrinkage during solidification [7].

The development of functionally graded materials (FGMs) emerged as a means to improve the toughness behaviour of composite materials, when compared to homogeneously reinforced composites; this improvement is due to the balanced contributions of reinforced and non-reinforced regions within the composite [8-9]. In particular, extensive work has been performed regarding centrifugal casting of aluminium-based functionally graded composites reinforced by solid ceramic particles [8-15]. The resulting gradient is due to the segregation promoted by the centrifugal force applied to both constituents, which exhibit dissimilar densities. Several parameters influence the properties of FGMs: atmosphere in the neighbourhood of the melt, melt pouring temperature, mould temperature, thermal gradient across the moulds, solidification rate, centrifugal force and pouring rate. These parameters affect several phenomena when the liquid metal containing solid particles solidifies in the mould such as: interaction and/or chemical reactions between the solidification front and the moving particles; rate of variation of the melt viscosity during solidification; interaction between particles and liquid; or the initial position of the particles in the mould, before starting their movement in the liquid. The balance between these phenomena determines the effect in terms of particle distribution, overall microstructure and FGM properties [10-11].

In the present paper, the particle volume fraction and porosity volume fraction of centrifugally cast syntactic functionally graded metal matrix composites (SFGMMCs) is evaluated by quantitative image analysis of optical micrographs.

\section{Experimental}

Stir-casting of precursor composites. In this research,an $\mathrm{Al}-7 \mathrm{Si}-0.3 \mathrm{Mg}$ alloy (A356) reinforced with 5-10 vol\% $\mathrm{SiO}_{2}-\mathrm{Al}_{2} \mathrm{O}_{3}$ commercial microballoons supplied by $3 \mathrm{M}^{\mathrm{TM}}$ was used. The characteristics of the microballoons are given in Table 1.

Table 1 - Chemical composition and physical characteristics of microballoons.

\begin{tabular}{|c|c|c|c|c|c|c|c|c|c|c|}
\hline \multicolumn{7}{|c|}{ Composition (wt\%) } & Density & $\begin{array}{c}\text { Surface } \\
\text { area } \\
{\left[\mathrm{g}^{2} \mathrm{~cm}^{-3}\right]}\end{array}$ & $\begin{array}{c}\text { Median } \\
\text { size } \\
{[\mu \mathrm{m}]}\end{array}$ \\
\hline $\mathrm{SiO}_{2}$ & $\mathrm{Al}_{2} \mathrm{O}_{3}$ & $\mathrm{~K}_{2} \mathrm{O}$ & $\mathrm{Fe}_{2} \mathrm{O}_{3}$ & $\mathrm{TiO}_{2}$ & $\mathrm{Na}_{2} \mathrm{O}$ & $\mathrm{CaO}$ & $\mathrm{MgO}$ & \\
\hline 57.79 & 30.27 & 2.53 & 3.89 & 1.02 & 0.56 & 0.70 & 1.23 & 0.82 & 0.83 & 48.77 \\
\hline
\end{tabular}

The MMCs were fabricated by a conventional stir-casting technique. The alloy was melted at $630^{\circ} \mathrm{C}$ under a $\mathrm{N}_{2}$ atmosphere in a graphite crucible inside a resistance furnace. Before adding the microballoons, these were preheated at $450{ }^{\circ} \mathrm{C}$ for 1 hour to eliminate humidity and to minimize chilling of the metallic mass Mechanical stirring was initiated before the addition of the microsballoons and maintained thereafter for 7 minutes (stirring speed; $300 \mathrm{rpm}$ ).

Centrifugal casting of functionally graded composites. Radial centrifugal casting was used to produce the functionally graded $\mathrm{Al} / \mathrm{SiO}_{2}-\mathrm{Al}_{2} \mathrm{O}_{3}$ from the precursor composites. The precursor composite was heated under an $\mathrm{Ar}$ atmosphere at $850^{\circ} \mathrm{C}$, It was then directly poured into a rotating mould rotating at $750 \mathrm{rpm}$ for 1 minute, in order to obtain a ring-like SFGMMC(length: $\sim 50 \mathrm{~mm}$; outer diameter: $\sim 80 \mathrm{~mm}$; inner diameter: $\sim 55 \mathrm{~mm}$ ).

Metallographic sample preparation. Samples were cut from the fabricated SFGMMC rings and were grinded with 240, 400, 800 and 1200 grit SiC papers. The polishing was finished with 6, 3 and $1 \mu \mathrm{m}$ diamond paste. Subsequently, the samples were ultrasonically cleaned in propanol for 5 minutes and then in distilled water for 5 minutes and finally dried in hot air. 
Characterization. Quantitative image analysis of optical micrographs with Image J Version $1.37 \mathrm{v}$ software allowed the measurement of the volume fractions for the particles and the voids in inner, intermediate and outer zones of the centrifugally cast samples. The outer surface of the ring is therefore represented as the 0.0 position of the normalized distance, whereas the inner surface corresponds to the 1.0 position - Fig. 1. Given that the wall thickness of the microballoons used is relatively small when compared to the diameter, the difference between the volume fractions of microballons $\left(\mathrm{V}_{\mathrm{S}}\right)$ and cavities $\left(\mathrm{V}_{\mathrm{H}}\right)$ in the composites will not be large, and this allows the use of $\mathrm{V}_{\mathrm{H}}$ as a rough estimate of $\mathrm{V}_{\mathrm{S}}$. The composite were observed by optic microscopy. The constituents were analyzed by XRD.

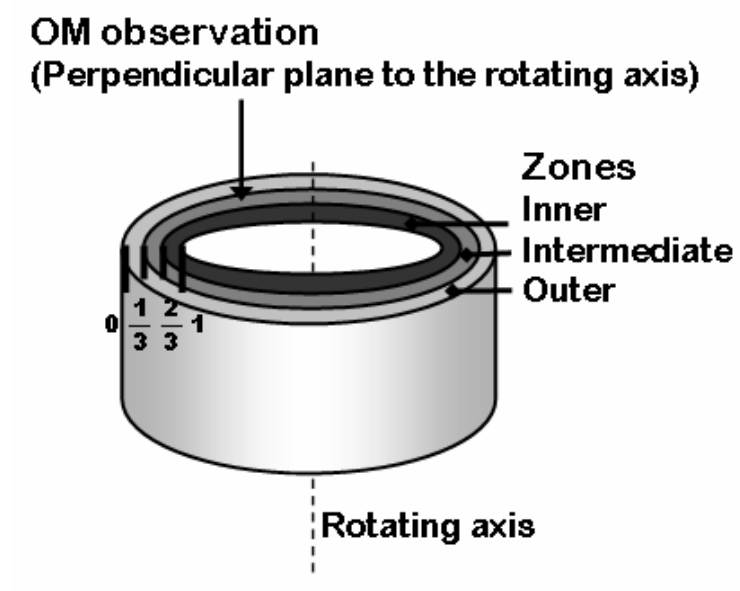

Figure 1 - Ring-shaped SFGMMC showing the mapped regions along the radial direction.

\section{Results and discussion}

Microstructure characterization. Fig. 2 shows the microstructures of the $\mathrm{A} 356 / 5 \mathrm{vol} \% \mathrm{SiO}_{2}$ $\mathrm{Al}_{2} \mathrm{O}_{3}$ SFGMMC for the outer, intermediate and inner zones of ring, respectively. The difference in grain size observed between outer and intermediate zones must be due the solidification rate in centrifugal casting: the liquid metal comes into contact with the cold mould walls and as a result solid nuclei form, creating a chilled region. Also noticeable is the fact that both these zones are nearly depleted of microballoons. Instead, the vast majority of these remains confined in the inner zone of the ring, in both the 5 and $10 \mathrm{vol} \%$ SFGMMCs. This may be essentially attributed to the large difference in the constituents densities (2.7 for aluminium and 0.82 for the particles), even if one must bear in mind that the solidification process of FGMs is complex, being subject to many different influences (mass, and heat transport, interactions between particles and of these with the solidifying matrix) and therefore affected by several operation parameters (pouring and mould temperatures, velocity of mould rotation) which can considerably influence the compositional gradient in the composite [11].

Volume Fraction of Reinforcement and Pores. The micrographs shown in Fig. 3 present the microballoon distribution in a $10 \mathrm{vol} \%$ SFGMMC centrifugally cast at $750 \mathrm{rpm}$. Fig. 4 shows the total area fraction of voids measured in each SFGMC. In both cases, the presence of reinforcements was observed essentially in inner zone of the ring, with an abrupt variation of the reinforcement concentration when transitioning between the inner and the intermediate zones.

On the other hand, in both cases, the level of matrix porosity in the inner zone is consistenly higher than what is observed throughout the other regions. but no significant variation could be detected when the overall reinforcement volume fraction was increased. This could be due to the increase in the apparent viscosity of the semisolid slurry caused by the larger number of particles (self-induced viscous drag) [16], which limits the slurry's ability to discharge trapped gases. A further cause for the porosity increase could be the inability of the melt to infiltrate the micrometersized crevices in the inefficiently packed ceramic particles [17]. 


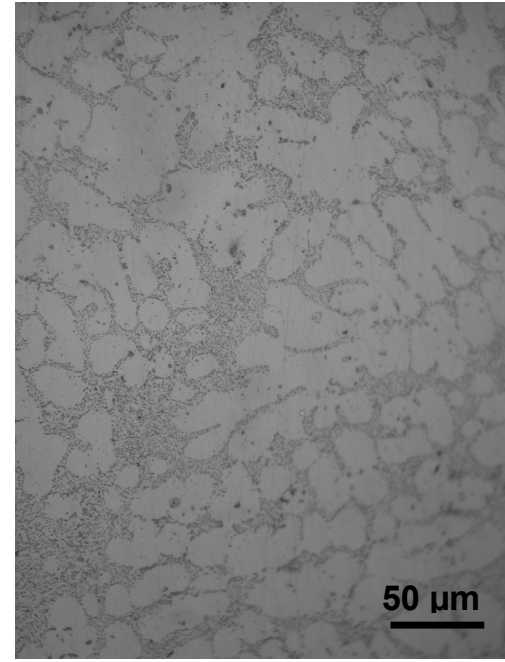

Outer zone

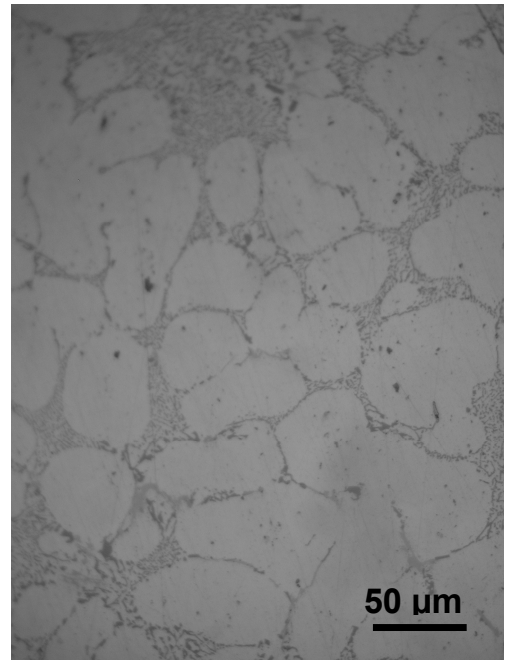

Intermediate zone

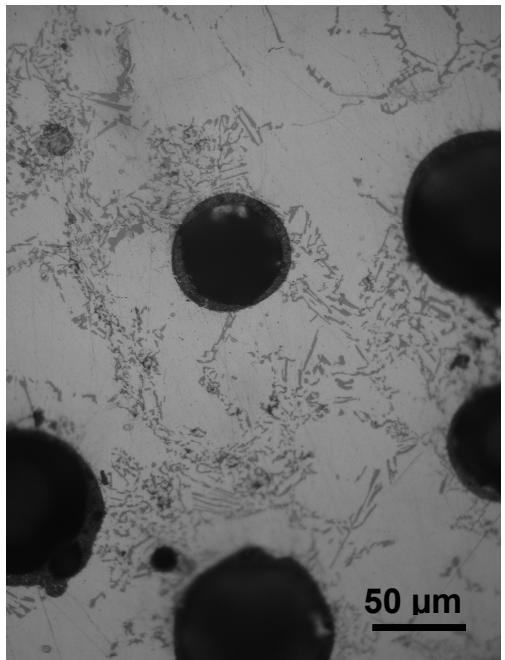

Inner zone

Figure 2 - Microstructures of the ring-shaped A356 / 5 vol\% $\mathrm{SiO}_{2}-\mathrm{Al}_{2} \mathrm{O}_{3} \mathrm{SFGMMC}$.

There are several factors affecting porosity such as pouring rates too slow, low casting temperatures, and filling mould problems among others. It is therefore important to determine the level of porosity present in these SFGMMCs.

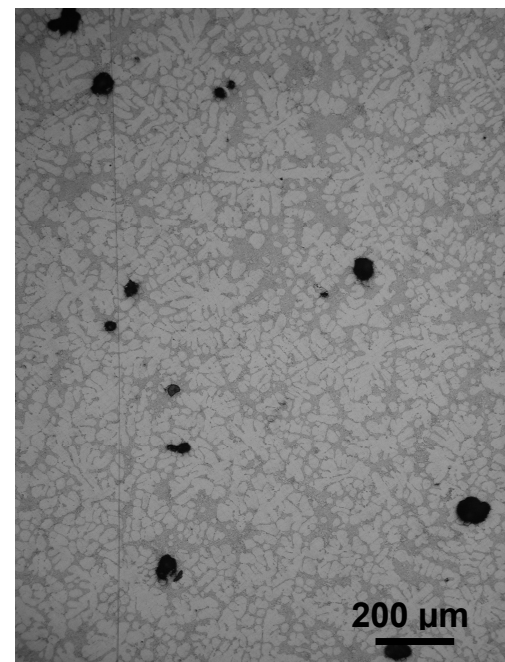

Outer zone

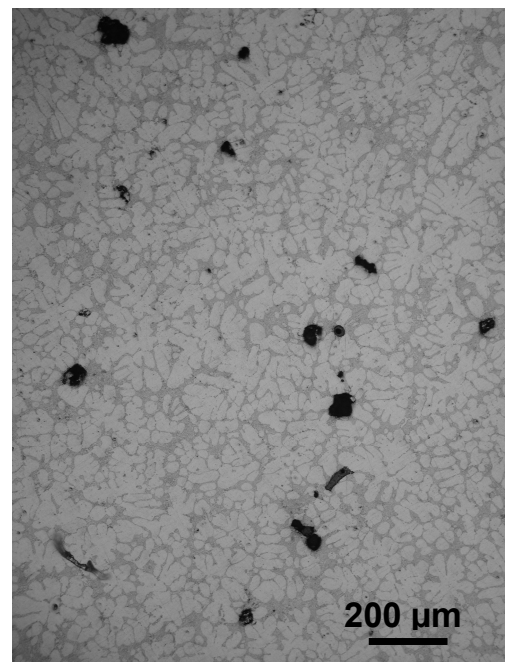

Intemediate zone

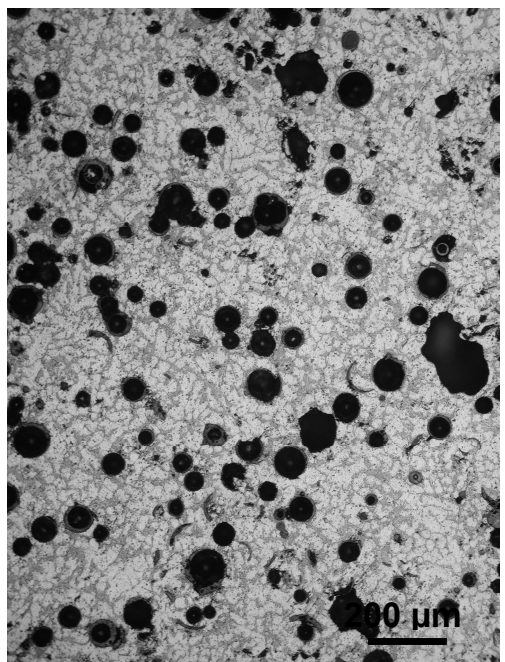

Inner zone

Figure 3 - Microstructures of $\mathrm{Al} / \mathrm{SiO}_{2}-\mathrm{Al}_{2} \mathrm{O}_{3} 5$ and 10 vol\% SFGMMCs correspond to outer, interior and inner zones of the fabricated rings, respectively.

\section{Conclusions}

The results in this work show that the centrifugal casting conditions induced variations of grain size between the outer and inner peripheries of $\mathrm{Al} / \mathrm{SiO}_{2}-\mathrm{Al}_{2} \mathrm{O}_{3} 5$ and $10 \mathrm{vol} \% \mathrm{SFGMMC}$. Additionally, a steep reinforcement distribution gradient was observed between the intermediate and the inner zones, the microballoons tending to remain confined to the latter. Also, the presence of reinforcement particles seems to induce a higher matrix porosity level in the inner zone, as compared to the microballoon-depleted zones. 

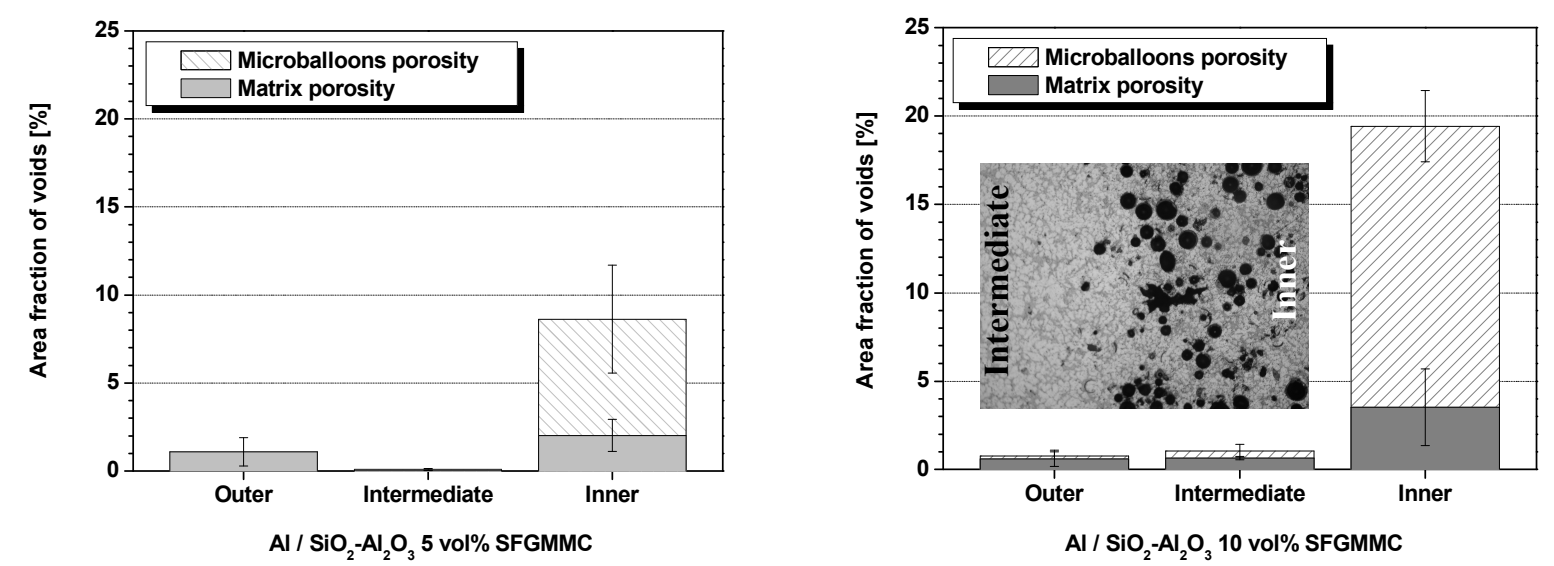

Figure 4 - Measured area fraction of voids in the $\mathrm{Al} / \mathrm{SiO}_{2}-\mathrm{Al}_{2} \mathrm{O}_{3} 5$ and 10 vol\% SFGMMC samples as a function of distance.

\section{Acknowledgements}

The authors wish to acknowledge Fundação para a Ciência e Tecnologia for funding under the program POCI (contract POCI/CTM/56395/2004) and the plurianual funding of CENIMAT.

\section{References}

[1] P.K. Rohatgi, J.K. Kim, N. Gupta, S. Alaraj and A. Daoud: Composites: Part A Vol.37 (2006), p 430.

[2] D.K. Balch, J.G. O'Dwyer, G.R. Davis, C.M. Cady, G.T. Gray and D.C. Dunand: Mater. Sci. Eng. A Vol. 328 (2005), p.408.

[3] M.Y. He, B.Wu and F.W. Zok: Mech. Mater. Vol. 20 (1995), p. 315.

[4] M. Kiser, M.Y. He and F.W. Zok: Acta Mater. Vol. 47(1999), p. 2685.

[5] N. Gupta and W. Ricci: Mater. Sci. Eng. A Vol. 427 (2006), p. 331.

[6] D.K. Balch and D.C. Dunand: Acta Mater. Vol. 54 (2006), p. 1501.

[7] J. Hashim, L. Looney and M.S.J. Hashmi: J. Mater. Proc. Tech. Vol. $92-93$ (1999), p. 1.

[8] R. Rodrigues-Castro and M.H. Kelestemur: J. Mater. Sci. Vol. 37 (2002), p. 1813.

[9] R. Rodríguez-Castro, R.C. Wetherhold and M.H. Kelestemur, Mater. Sci. Eng. A Vol. 323 (2002), p. 445.

[10] J.W. Gao and C.Y. Wang: Mater. Sci. Eng. Vol. A292 (2000), p. 207.

[11]J.W. Gao and C.Y. Wang: J. Heat Transfer Vol. 123 (2001), p.1.

[12]P.M. Biesheuvel and H. Verweij: J. Am. Ceram. Soc. Vol. 83 (2000), p. 743.

[13]Y. Watanabe and Y. Fukui, in: Microscopic Study of Al-base Intermetallic Compound dispersed Functionally Graded Materials Fabricated by a Centrifugal Method, edited by A. Méndez-Vilas and L. Labajos-Broncano, Current Issues on Multidisciplinary Microscopy Research and Education, FORMATEX Microscopy Book Series, No 2, Badajoz, Spain (2003) p. 189-198.

[14]A. Velhinho, P.D. Sequeira, R. Martins, G. Vignoles, F.B. Fernandes, J.D. Botas and L.A. Rocha: Nuclear Instr. \& Methods in Phys. Res B Vol. 200 (2003), p. 295.

[15]N.B. Duque, Z.H. Melgarejo and O.M. Suárez: Mater. Characterization Vol. 55 (2005), p. 167.

[16] S. Nai, M. Grupta and C Lim: Mater. Sci. Tech. Vol.20 (2004), p.57.

[17]A. Velhinho, P.D. Sequeira, F.M. Braz Fernandes, J.D. Botas, L.A. Rocha: Mater. Sci. Forum Vol. 423-425 (2003), p. 25. 